\title{
Optimization of levofloxacin-loaded crosslinked chitosan microspheres for inhaled aerosol therapy
}

\author{
Marisa C. Gaspar ${ }^{\mathrm{a}, \mathrm{b}, *}$, João J.S. Sousa ${ }^{\mathrm{a}, \mathrm{b}}$, Alberto A.C.C. Pais ${ }^{\mathrm{c}}$, Olga Cardoso $^{\mathrm{d}}$, Dina Murtinho ${ }^{\mathrm{c}}$, \\ M. Elisa S. Serra ${ }^{c}$, Frédéric Tewes ${ }^{\mathrm{e}, \mathrm{f}}$, Jean-Christophe Olivier ${ }^{\mathrm{e}, \mathrm{f}}$ \\ ${ }^{a}$ Center for Neuroscience and Cell Biology, University of Coimbra, 3000-548 Coimbra, Portugal \\ b Laboratory of Pharmaceutical Technology, Faculty of Pharmacy, University of Coimbra, Pólo das Ciências da Saúde, Azinhaga de Santa Comba, 3000-548 Coimbra, Portugal \\ 'Chemistry Department, University of Coimbra, 3004-535 Coimbra, Portugal \\ ${ }^{\mathrm{d}}$ Laboratory of Microbiology, Faculty of Pharmacy, University of Coimbra, Pólo das Ciências da Saúde, Azinhaga de Santa Comba, 3000-548 Coimbra, Portugal \\ e INSERM, U 1070, Pôle Biologie Santé, 1 rue Georges Bonnet, TSA 51106, 86073 Poitiers Cedex 9, France \\ ${ }^{\mathrm{f}}$ University of Poitiers, Faculty of Medicine and Pharmacy, 6 rue de la Milétrie, TSA 51115, 86073 Poitiers Cedex 9, France
}

\section{A R T I C L E I N F O}

\section{Article history:}

Received 23 April 2015

Revised 9 July 2015

Accepted in revised form 11 July 2015

Available online 17 July 2015

\section{Keywords:}

Experimental design

Cystic Fibrosis

Crosslinking agents

Chitosan

Microspheres

Levofloxacin

Aerosol

Lung delivery

\begin{abstract}
A B S T R A C T
The aim of this work was the development of innovative levofloxacin-loaded swellable microspheres (MS) for the dry aerosol therapy of pulmonary chronic Pseudomonas aeruginosa infections in Cystic Fibrosis patients. In a first step, a factorial design was applied to optimize formulations of chitosan-based MS with glutaraldehyde as crosslinker. After optimization, other crosslinkers (genipin, glutaric acid and glyceraldehyde) were tested. Analyses of MS included aerodynamic and swelling properties, morphology, drug loading, thermal and chemical characteristics, in vitro antibacterial activity and drug release studies. The prepared MS presented a drug content ranging from $39.8 \%$ to $50.8 \%$ of levofloxacin in an amorphous or dispersed state, antibacterial activity and fast release profiles. The highest degree of swelling was obtained for MS crosslinked with glutaric acid and genipin. These formulations also presented satisfactory aerodynamic properties, making them a promising alternative, in dry-powder inhalers, to levofloxacin solution for inhalation.
\end{abstract}

(c) 2015 Elsevier B.V. All rights reserved.

\section{Introduction}

Cystic Fibrosis (CF) is an inherited autosomal recessive disease caused by various mutations of the Cystic Fibrosis Transmembrane Conductance Regulator (CFTR) gene, resulting in the malfunction of chloride channels and consequently multiple organ failure. In the lungs, the consequence is a viscid mucus which is responsible for the dysfunction of the lung microorganism clearance system and for the clinical symptoms, i.e. chronic inflammation and bacterial infection that eventually leads to respiratory failure [1].

Abbreviations: CF, Cystic Fibrosis; CFTR, Cystic Fibrosis Transmembrane Conductance Regulator; DL, drug loading; ED, emitted dose; EE, entrapment efficiency; FPF, fine particle fraction; GA, glutaric acid; GL, glutaraldehyde; GLY, D,L-Glyceraldehyde; GNP, genipin; LVX, levofloxacin; MMAD, mass median aerodynamic diameter; MS, microspheres; NGI, Next Generation Impactor.

* Corresponding author at: Laboratory of Pharmaceutical Technology, Faculty of Pharmacy, University of Coimbra, Pólo das Ciências da Saúde, Azinhaga de Santa Comba, 3000-548 Coimbra, Portugal. Tel.: +351 239488400.

E-mail address: mgaspar@ff.uc.pt (M.C. Gaspar).
Pseudomonas aeruginosa chronic infection is considered as the main cause of mortality in adult CF patients [2]. Treatment consists of intensive antibiotherapy to prevent the onset of chronicity and the occurrence of resistance. Tobramycin, aztreonam and colistimethate, a prodrug of colistin, are available in efficient products for inhalation and represent a valuable alternative to solution for injection or oral therapy. A levofloxacin (LVX) inhalation solution is currently in clinical trials in CF patients [3-6,8] and results from Phase $2 \mathrm{~b}$ trial demonstrated reduction of $P$. aeruginosa in sputum as well as improvements in lung function [7]. However, the compliance to inhaled therapy has to be improved and some innovative formulations have appeared in recent years, including nanospheres, microspheres (MS) and liposomes [8,9]. We recently reviewed some advantages of dry-powder inhalers over liquid aerosols, among the main ones on compliance: quicker administration and a simpler, more hygienic procedure [10]. In this context, this work focused on the development of an immediate-release formulation of dry powder LVX for inhalation, based on polymeric MS. For appropriate deposition in the lungs, aerosolized MS should possess an 
Table 1

Coding of independent variables $x$ for MS preparation.

\begin{tabular}{|c|c|c|c|c|c|}
\hline & & \multicolumn{4}{|c|}{ Coded levels of independent variables $x$} \\
\hline & & $\underline{x_{1}}$ & $x_{2}$ & $x_{3}$ & $x_{4}$ \\
\hline \multirow{3}{*}{\multicolumn{2}{|c|}{$\begin{array}{l}\text { Description of variables and } \\
\text { coding }\end{array}$}} & Presence of LVX ${ }^{\mathrm{a}}$ & Chitosan concentration & GL amount & Inlet temperature \\
\hline & & $-1(\mathrm{No})$ & $-1(0.25 \%(\mathrm{w} / \mathrm{v}))$ & -1 (5 mmol per g chitosan) & $-1\left(120^{\circ} \mathrm{C}\right)$ \\
\hline & & +1 (Yes) & $+1(0.5 \%(\mathrm{w} / \mathrm{v}))$ & +1 (10 mmol per g chitosan) & $+1\left(175^{\circ} \mathrm{C}\right)$ \\
\hline \multirow[t]{16}{*}{ Formulations } & $\mathrm{F} 1$ & -1 & -1 & -1 & -1 \\
\hline & $\mathrm{F} 2$ & -1 & -1 & +1 & -1 \\
\hline & F3 & -1 & -1 & -1 & +1 \\
\hline & $\mathrm{F} 4$ & -1 & -1 & +1 & +1 \\
\hline & F5 & -1 & +1 & -1 & -1 \\
\hline & F6 & -1 & +1 & +1 & -1 \\
\hline & F7 & -1 & +1 & -1 & +1 \\
\hline & F8 & -1 & +1 & +1 & +1 \\
\hline & F9 & +1 & -1 & -1 & -1 \\
\hline & F10 & +1 & -1 & +1 & -1 \\
\hline & F11 & +1 & -1 & -1 & +1 \\
\hline & F12 & +1 & -1 & +1 & +1 \\
\hline & F13 & +1 & +1 & -1 & -1 \\
\hline & F14 & +1 & +1 & +1 & -1 \\
\hline & F15 & +1 & +1 & -1 & +1 \\
\hline & F16 & +1 & +1 & +1 & +1 \\
\hline
\end{tabular}

a 1:1 LVX:chitosan weight ratio.

aerodynamic size between 1 and $5 \mu \mathrm{m}$, which corresponds to the spherical equivalent geometric size of a particle having a density of $1 \mathrm{~g} / \mathrm{cm}^{3}$ [11]. MS of this size are, however, phagocytosed by the lung macrophages, which in turn may induce toxicity to macrophages or modify the availability of the drug. In order to avoid such phagocytosis, some authors proposed to formulate "swelling" MS, i.e. MS able to swell upon hydration after deposition in the lung epithelial lining fluid $[12,13]$. Chitosan is an example of polymer with swelling capacity, biodegradability, biocompatibility, nontoxicity, as well as antibacterial and anti-inflammatory properties $[14,15]$. Besides, MS made of chitosan possess bioadhesive properties, promoting adhesion to the pulmonary system [16].

The aim of this work was the preparation of chitosan LVX-loaded MS by the spray drying method. A factorial planning was applied for MS crosslinked with glutaraldehyde (GL) in order to evaluate the influence of some parameters (chitosan and crosslinker concentration, inlet temperature and presence of drug) on the MS size. After the optimization process, other chemical crosslinkers were also considered to control the swelling magnitude of the microspheres, to maintain the microsphere structure $[17,18,12,13]$ and to facilitate the spray-drying process $[19,20,9]$. Such properties allow the drug to be delivered directly to the lungs avoiding phagocytosis after lung deposition. The crosslinkers studied in the present work included glutaraldehyde (GL), genipin (GNP), glutaric acid (GA) and DL-glyceraldehyde (GLY). GL is a widely-used crosslinker and has already been applied to chitosan MS $[21,16,22]$. The three other crosslinking agents present lower toxicity. GNP demonstrated levels of toxicity 5000-10,000 times lower than GL and is a natural agent obtained from geniposide, a compound isolated from the fruits of the Gardenia jasminoides Ellis plant. Cytotoxicity studies on A549 and Calu-3 cells have shown significant lower cytotoxicity of GNP when compared with GL and sodium tripolyphosphate $[23,24,16,25]$. GA is found in plant and animal tissues and considered to be non-toxic. Cell viability assays with GA-crosslinked chitosan suggested no significant difference with the polymer itself [26,27]. GLY is also nontoxic and biocompatible, being found in the human organism as a metabolic product of fructose [28-30]. Analyses of the obtained MS included aerodynamic size, morphology, swelling properties, drug loading, thermal and chemical characteristics, in vitro antibacterial and drug release studies.

\section{Materials and methods}

\subsection{Materials}

Chitosan low molecular weight $(20,000$ cps, $75-85 \%$ deacetylated), glutaraldehyde (GL) $50 \% \quad(w / w)$ aqueous solution, Phosphate buffered saline (PBS) tablets, Whatman ${ }^{\circledR}$ qualitative filter paper, Grade 1 (11- $\mu \mathrm{m}$ pore size), and DL-glyceraldehyde ( $\geqslant 90 \%$ by GC) were obtained from Sigma-Aldrich ${ }^{\circledR}$ (France). Glacial acetic acid was obtained from Panreac ${ }^{\circledR}$ (Spain). Levofloxacin hemihydrate was kindly provided by Tecnimede S.A. (Portugal). PIC B7 was obtained from Waters ${ }^{\circledR}$ (France). Formic acid $99-100 \%$ AnalaR (NormaPur) was obtained from VWR ${ }^{\circledR}$ (France) and acetonitrile of HPLC grade was purchased from Carlo Erba reagents (France). Genipin (98\% purity) was obtained from Challenge Bioproducts Co., Ltd. (Taiwan). Glutaric acid (99\% purity) was purchased from Merck ${ }^{\circledR}$ (Portugal). All other chemicals were of analytical grade or equivalent. Purified water was produced using a MilliQ gradient ${ }^{\circledR}$ Plus Millipore system.

\subsection{Preparation of chitosan MS}

The formulations and operational parameters were first optimized using GL as a standard crosslinker and resorting to a factorial design approach (see Table 1). For the MS preparation, chitosan was dissolved under magnetic stirring $(300 \mathrm{rpm})$ in $150 \mathrm{~mL}$ of $1 \%(\mathrm{w} / \mathrm{v})$ acetic acid solution $\left(3 \mathrm{~h}\right.$ at $50{ }^{\circ} \mathrm{C}$, then overnight at room temperature) and solutions were paper-filtered. LVX was added according to the specified weight ratios and solutions were stirred for $30 \mathrm{~min}$. After addition of GL, crosslinking reaction was performed under stirring for 15 min [19]. The mixtures were then spray dried using a Büchi ${ }^{\circledR}$ Mini Spray Dryer B-290 (Switzerland) setup in blowing mode and equipped with a $0.7 \mathrm{~mm}$ nozzle. Constant settings were as follows: $10 \mathrm{~mL} / \mathrm{min}$ pump rate, $473 \mathrm{~L} / \mathrm{h}$ air flow rate and aspiration rate of $100 \%$. The two inlet temperatures studied, $120^{\circ} \mathrm{C}$ or $175^{\circ} \mathrm{C}$, resulted in outlet temperatures of $45-60{ }^{\circ} \mathrm{C}$ and $65-80^{\circ} \mathrm{C}$, respectively. Table 1 details the formulations and conditions for the factorial planning. The optimized conditions and formulation were deduced from the factorial planning and were finally applied to other crosslinkers. Conditions during the crosslinking step were however adapted to the crosslinker 
chemical reactivity, based on literature's reports. For GNP (0.2 mmol per g chitosan), crosslinking reaction was carried out at $50{ }^{\circ} \mathrm{C}$ for $3 \mathrm{~h}$ under magnetic stirring (300 rpm) (adapted from [16]). For GLY ( $1 \mathrm{mmol} / \mathrm{g})$, crosslinking was carried out at RT for $30 \mathrm{~min}$ (same stirring conditions) [28] and for GA $(1 \mathrm{mmol} / \mathrm{g})$ crosslinking was carried out at $60^{\circ} \mathrm{C}$ for $2 \mathrm{~h}$ (same stirring conditions) $[27,26,31]$. MS were collected and stored at $5 \pm 3{ }^{\circ} \mathrm{C}$ in vacuum desiccators on silica gel.

\subsection{Optimization}

\subsubsection{Factorial design}

The factorial approach was performed for MS crosslinked with GL in order to optimize geometric size, for which determination is faster than aerodynamic size in the formulation development stage. This experimental design included four independent variables $\left(x_{1}\right.$ to $\left.x_{4}\right)$ and two coded levels $(-1,+1)$ (Table 1$)$. The values at each level were chosen considering acceptable domains for each variable and according to therapeutic approach and published works $[19,20,32,33]$. Programs developed by the authors with GNU Octave software [34] were used to solve the polynomial multilinear model: $D=\beta_{0}+\beta_{1} x_{1}+\beta_{2} x_{2}+\beta_{3} x_{3}+\beta_{4} x_{4}+\beta_{12} x_{1} x_{2}+$ $\beta_{13} x_{1} x_{3}+\beta_{14} x_{1} x_{4}+\beta_{23} x_{2} x_{3}+\beta_{24} x_{2} x_{4}+\beta_{34} x_{3} x_{4}$, where $\beta_{0}$ was the arithmetic mean response, $\beta_{1}-\beta_{4}$ the coefficients of the respective independent variables and $\beta_{12}, \beta_{13}, \beta_{14}, \beta_{23}, \beta_{24}$ and $\beta_{34}$ the interaction between variables. The response $D$ (dependent variable) corresponded to the mean diameter of the MS from the volume distribution. This model was applied to evaluate the effects and interactions of the variables. For the statistical analysis, Student's $t$-test was performed with a significance level of $95 \%$.

\subsubsection{Particle size analysis}

MS were dispersed in purified water, sonicated for $10 \mathrm{~min}$ and analyzed using laser light diffraction (Microtrac ${ }^{\circledR} \mathrm{X} 100$ particle size analyzer) as previously described [35]. Three measurements were carried out for each sample and particle size expressed as the mean diameter \pm SD of the volume distribution $\left(D_{v}\right)$ was calculated using the Microtrac Particle Size Analyzer application program (version $9.0 \mathrm{~g})$.

\subsection{MS characterization}

\subsubsection{Scanning electron microscopy (SEM)}

Samples were dispersed on double-sided adhesive carbon tapes that were fixed on aluminum stubs. They were then sputter coated with a gold film making them conducting. SEM images were taken using a Jeol JSM 6010 LV electron microscope (Tokyo, Japan) with the primary electrons accelerated under a voltage of $15 \mathrm{kV}$. The images were obtained from the collection of secondary electrons at a working distance of $11 \mathrm{~mm}$.

\subsubsection{Powder X-ray Diffraction (XRD)}

Samples were placed in a low background silicon holder in Bragg-Brentano configuration, with a copper tube powered at $45 \mathrm{kV}$ and $40 \mathrm{~mA}$. They were scanned in the range $5^{\circ}<2 \theta<145^{\circ}$ at a step of $0.066^{\circ}$ and time/step of $10 \mathrm{~s}$ in an Empyrean PANalytical (The Netherlands) diffractometer with the detector Xcelerator in scanning mode and opened at $2^{\circ}$. A nickel filter was installed in a secondary optic in order to eliminate the $K \beta$ component.

\subsubsection{Differential Thermal Analysis/Thermal Gravimetric Analysis (DTA/TGA)}

MS were analyzed by combined DTA/TGA that were performed on a SDT Q600 Instrument (TA, USA) from $30^{\circ} \mathrm{C}$ to $300^{\circ} \mathrm{C}$ with a $10^{\circ} \mathrm{C} / \mathrm{min}$ heating rate and under a $100 \mathrm{~mL} / \mathrm{min}$ air flow rate. The calibration procedure was performed with sapphire, using empty platinum pans as reference.

\subsubsection{Attenuated total reflectance Fourier transform infrared spectroscopy (ATR-FTIR)}

ATR infrared spectra were recorded using a FT-IR $6700 \mathrm{spec}-$ trometer (Thermo Scientific Nicolet ${ }^{\mathrm{TM}}$, USA) equipped with an ATR accessory. Samples were placed in the ATR device and measurements were made by using 16 scans between 4000 and $650 \mathrm{~cm}^{-1}$ for each spectrum with a resolution of $4 \mathrm{~cm}^{-1}$.

\subsubsection{Swelling properties}

Studies concerning the swelling behavior of MS were also conducted. A known amount ( $20 \mathrm{mg} \pm 1 \mathrm{mg}$ ) of MS was added to $1 \mathrm{~mL}$ of PBS ( $\mathrm{pH}$ 7.4). After dispersion with a vortex, the MS suspensions were mixed at $350 \mathrm{rpm}$ and $37 \pm 0.5^{\circ} \mathrm{C}$ by using a Thermomixer (Thermomixer ${ }^{\circledR}$ Comfort, Eppendorf AG., Hamburg, Germany). At predetermined points, samples were centrifuged at $10,000 \mathrm{rpm}$ for $5 \mathrm{~min}$ (Eppendorf ${ }^{\circledR}$ Centrifuge 5418R, Germany) and supernatants were removed. Weight of swollen MS was determined. The percentage of swelling was calculated as follows: Swelling $(\%)=\left(W_{t} / W_{i}\right) \times 100$, where $W_{t}$ corresponds to the weight of swollen MS at time $t$ and $W_{i}$ to the initial weight [13]. Experiments were done in triplicate and results were expressed as mean \pm SD.

\subsubsection{Drug loading and entrapment efficiency}

LVX-loaded MS $(10 \pm 1 \mathrm{mg})$ were submitted to an extraction process with $20 \mathrm{~mL}$ of $0.1 \mathrm{M}$ hydrochloric acid [36] for $3 \mathrm{~h}$ at room temperature, under magnetic stirring (300 rpm) and protected from light. An aliquot $(1 \mathrm{~mL})$ of each suspension was collected and centrifuged at $3500 \mathrm{rpm}$ for $5 \mathrm{~min}$ (Hettich ${ }^{\circledR}$ Zentrifugen Universal 320R, Germany). Supernatants were collected and appropriately diluted in PBS prior to HPLC quantification. Drug loadings (DL) (\%) were expressed as the amount of LVX (mg) per mg of MS (including entrapped LVX). Entrapment efficiencies (EE) (\%) were calculated as the percent ratios of the determined contents to the theoretical contents calculated considering a 100\% EE [9]. All the experiments were done in triplicate.

\subsubsection{LVX HPLC determination}

The chromatographic system consisted of an L-2200 autosampler unit (Lachrom Elite ${ }^{\circledR}$, Hitachi), an L-2130 pump (Lachrom Elite $^{\circledR}$, Hitachi) and an Intelligent Fluorescence Detector JASCO FP-920. It was equipped with a C18 X-Bridge ${ }^{\mathrm{TM}}$ HPLC column ( $5 \mu \mathrm{m}, 2.1 \times 100 \mathrm{~mm}$, Waters). The mobile phase was run at a $0.25 \mathrm{~mL} / \mathrm{min}$ flow rate and was composed of a 20:80 (v/v) acetonitrile:water mixture supplemented with $0.1 \%(\mathrm{v} / \mathrm{v})$ formic acid and $0.2 \%(\mathrm{v} / \mathrm{v})$ PIC B7. The injection volume was $10 \mu \mathrm{L}$ and the run time was $8 \mathrm{~min}$. LVX was detected by fluorometry $\left(\lambda_{\mathrm{ex}}=290 \mathrm{~nm}\right.$; $\lambda_{\mathrm{em}}=460 \mathrm{~nm}$ ). The calibration curve was constructed by linear regression of the peak areas versus the added concentrations $(0.156-5 \mu \mathrm{g} / \mathrm{mL}$ in PBS ( $\mathrm{pH} 7.4))$ with a weighting factor of $1 / x^{2}$ $\left(R^{2}=0.999\right)$. Appropriate quality controls (QCs) were also included to monitor the performance of the method.

\subsection{In vitro studies}

\subsubsection{In vitro deposition studies using Next Generation Impactor (NGI)}

The aerodynamic diameter was measured using a Next Generation Impactor (NGI, Copley Ltd., Nottingham, UK), equipped with a TPK 2000 critical flow controller and a HCP5 vacuum pump (Copley HCP5, Nottingham, UK). For each measurement, a size-three hard gelatin capsule was filled with $20 \pm 1 \mathrm{mg}$ of LVX-loaded MS powder, inserted in a dry-powder inhaler Handihaler $^{\circledR}$ (Boehringer-Ingelheim, Germany) and pierced. The inhaler was tightly connected to the NGI induction port via a 


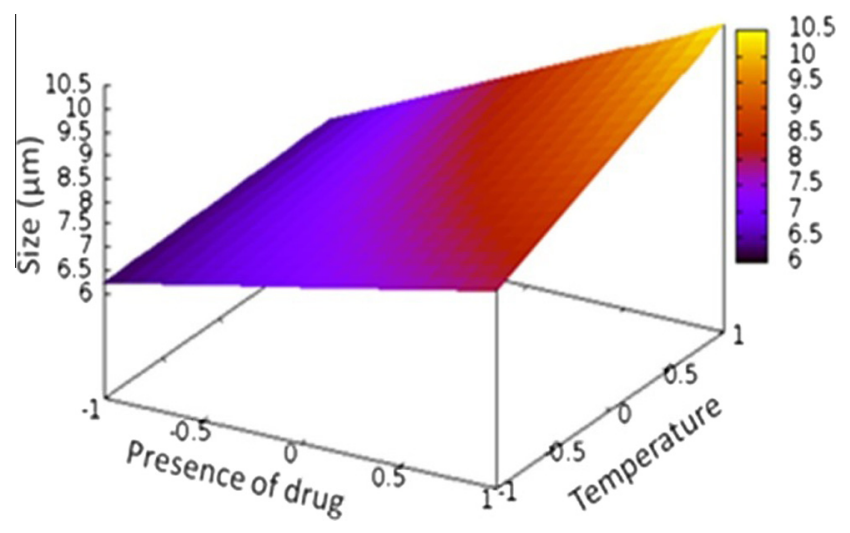

Fig. 1. Response surface for the main factors affecting the geometric size of MS: presence of drug and temperature (the other factors were set to zero in terms of codified values).

silicone adapter. The pump was turned on, allowing a constant air flow of $60 \pm 5 \% \mathrm{~L} / \mathrm{min}$ for $4 \mathrm{~s}$ (twice) in order to obtain $4 \mathrm{~L}$ of air from the adapter and through the NGI. The powder remaining in the capsule and deposited in the inhaler, the adapter, the induction port, all the stages and the filter was collected with $0.1 \mathrm{M}$ hydrochloric acid solution allowing extraction for LVX determination. The emitted dose (ED), i.e. the mass of LVX deposited in the induction port, the stages and the filter, was expressed as the percentage (ED\%) of the total recovered LVX mass (i.e. from the induction port, the stages and the filter NGI plus from the adapter, the inhaler and capsule). The fine particle dose (FPD), i.e. the fraction of LVX in particles with aerodynamic diameters below $5.0 \mu \mathrm{m}$, was calculated by interpolation, from the inverse of the standard normal cumulative mass percentage distribution, and considering stages 1 to 3 . The mass median aerodynamic diameter (MMAD) of the particles was calculated from a similar plot (considering stages 1 to 6 ) as the particle aerodynamic diameter at which the line crosses the 50\% mark [37-39]. The fine particle fraction (FPF) was calculated by converting the FPD mass as the percentage of the ED.

\subsubsection{In vitro $L V X$ release studies}

Release studies were performed at $37 \pm 0.5{ }^{\circ} \mathrm{C}$ in PBS ( $\mathrm{pH} 7.4$ ) under sink conditions. The LVX-loaded MS powder ( $15 \pm 1 \mathrm{mg}$ ) was dispersed in $150 \mathrm{~mL}$ PBS and the release medium was maintained under a uniform shaking of $250 \mathrm{rpm}$ using a VWR ${ }^{\circledR}$ incubating mini shaker. At pre-determined time points $1 \mathrm{~mL}$ aliquots were taken and centrifuged at $3500 \mathrm{rpm}$ for 5 min (Hettich ${ }^{\circledR}$ Zentrifugen Universal 320R, Germany). Then, $50 \mu \mathrm{L}$ of supernatant was collected for LVX HPLC determination. The remaining $950 \mu \mathrm{L}$ were vortex-mixed and added back to the flasks. Experiments were conducted in triplicate.

\subsubsection{In vitro antibacterial activity}

Antibacterial activity of free LVX was compared with chitosan and LVX-loaded chitosan MS by measuring the minimal inhibitory concentrations (MICs). Two P. aeruginosa strains (CF2_2004 and CF7_2005) isolated from sputum of two CF patients (Pediatric Unit, Coimbra Hospital Centre, CHC, Portugal) were used. Identification was made by both MicroScan WalkAway ${ }^{\circledR}$ (Dade Behring, West Sacramento, CA) and API ${ }^{\circledR}$ 20NE (Biomérieux Vitek, Inc. Hazelwood, Mo., USA) systems. The bacteria were incubated on Trypticase soy agar for $24 \mathrm{~h}$ at $37{ }^{\circ} \mathrm{C}$. Few colonies were transferred to physiological saline in order to obtain a 0.5 McFarland standard $\left(1.5 \times 10^{8} \mathrm{CFU} / \mathrm{mL}\right)$ inoculum, as described for the broth microdilution method $[40,41]$. In 96-well plates, Mueller-Hinton broth $(100 \mu \mathrm{L})$ and LVX solution or MS/chitosan suspensions in a $40 \%(\mathrm{v} / \mathrm{v})$ ethanol-water mixture $(100 \mu \mathrm{L})$ were added per well. These solutions/suspensions were then sequentially diluted (from 5 to $0.078 \mathrm{mg} / \mathrm{L}$ LVX). Then, $100 \mu \mathrm{L}$ of inoculum was added. Negative controls with MS suspensions (in all the concentrations) and growth controls were also included. After $24 \mathrm{~h}$ of incubation at $37^{\circ} \mathrm{C}$ and under $100 \mathrm{rpm}$, optical density was measured at $600 \mathrm{~nm}$ in a Synergy ${ }^{\mathrm{TM}}$ HT microplate reader (BioTek Instruments ${ }^{\circledR}$, Inc., Winooski, VT, USA). Values lower than 0.1 were considered as zero bacterial growth and the lowest concentration that yields an optical density value $<0.1$ indicated the MIC [42]. As a complementary study, the bacterial susceptibility was also evaluated by the disk diffusion test in Mueller-Hinton agar, measuring the diameter of the inhibition zone (mm) [41]. Experiments were done in three different occasions.

\section{Results and discussion}

\subsection{Optimization}

The first step of the process optimization was carried out with GL as crosslinker using factorial design. Some formulation parameters (presence of drug, $x_{1}$, chitosan concentration $\%(\mathrm{w} / \mathrm{v}), x_{2}$ and GL concentration ( $\mathrm{mmol} / \mathrm{g}), x_{3}$ ) and one operating condition (inlet temperature $\left.\left({ }^{\circ} \mathrm{C}\right), x_{4}\right)$ were investigated as their effect on the geometric diameter of MS, a crucial parameter for lung delivery using solid particles. Actually, the geometric size was useful in the screening step to foreseen the aerodynamic properties and it is much quicker to perform than the impactor measurements. The response function obtained from the factorial planning was as follows: $\quad D=7.78+1.43 x_{1}+0.26 x_{2}-0.33 x_{3}+0.63 x_{4}+0.27 x_{1} x_{2}-$ $0.01 x_{1} x_{3}+0.55 x_{1} x_{4}+0.09 x_{2} x_{3}-0.09 x_{2} x_{4}-0.11 x_{3} x_{4}$. The $\beta$ coefficient with the higher value corresponds to the higher effect on the particle size. A positive coefficient means an increasing effect in particle size and a negative one the opposite. In this case, the presence of drug $\left(\beta_{1}=1.43\right)$ and the inlet temperature $\left(\beta_{4}=0.63\right)$ were the main factors affecting the MS size, both in an increasing way with an increasing level of the variable. This result can be explained by the higher temperature that leads to a faster droplet evaporation and to polymer precipitation at the liquid-air interface, resulting in larger microspheres [43]. The presence of drug represents an amount of material that the chitosan matrix has to incorporate resulting also in larger particles, which is in accordance with some results already published that state that a higher amount of solute leads to larger particles [44-46,43]. In addition, the $\beta_{14}$ coefficient of interaction between these two factors shows a synergistic effect for particle growth (Fig. 1). The coefficients for the other variables corresponded to lower values and were not statistically significant (see $t$-values, Table 2). However, higher chitosan concentrations tend to be associated with larger particles $\left(\beta_{2}=0.26\right)$. Similar results have already been observed and were attributed to larger droplets formed when higher concentrations of the polymer increase the viscosity of the nebulized phase [37]. A slight decrease of size was also observed for MS crosslinked with a higher concentration of GL $\left(\beta_{3}=-0.33\right)$, which can be attributed to the tightly covalently bonded structure [47].

The geometric size of the MS prepared according to the experimental design ranged from $4.70 \pm 0.45 \mu \mathrm{m}$ to $12.65 \pm 2.82 \mu \mathrm{m}$, as indicated in Table 3 . The results from the factorial planning allowed the selection of parameters for MS with a suitable geometric size, also allowing a rapid preparation and good yield (Table 3 ), i.e. $0.5 \%(\mathrm{w} / \mathrm{v})$ chitosan, $120^{\circ} \mathrm{C}$ inlet temperature, and $5 \mathrm{mmol} / \mathrm{g} \mathrm{GL}$ concentration. Although $10 \mathrm{mmol} / \mathrm{g}$ concentration tends to reduce the size of MS by intermolecular tightening, it was observed that some powder adhered to the cyclone during the preparation 
Table 2

Coefficients obtained for model from the factorial design and respective $t$ value and significance level.

\begin{tabular}{|c|c|c|c|c|c|c|c|c|c|c|c|}
\hline Coefficients & $\beta_{0}$ & $\beta_{1}$ & $\beta_{2}$ & $\beta_{3}$ & $\beta_{4}$ & $\beta_{12}$ & $\beta_{13}$ & $\beta_{14}$ & $\beta_{23}$ & $\beta_{24}$ & $\beta_{34}$ \\
\hline Values & 7.78 & 1.43 & 0.26 & -0.33 & 0.63 & 0.27 & -0.01 & 0.55 & 0.09 & -0.09 & -0.11 \\
\hline$t$ value & 37.5 & 6.9 & 1.3 & -1.6 & 3.0 & 1.3 & -0.1 & 2.7 & 0.4 & -0.4 & -0.5 \\
\hline Significance level & 100.0 & 100.0 & 76.9 & 86.7 & 99.0 & 77.5 & 3.9 & 97.9 & 33.6 & 33.5 & 38.1 \\
\hline
\end{tabular}

Table 3

Particle size of MS for formulations used in factorial planning and corresponding values of Yield (\%), DL (\%) and EE (\%). Results are expressed as mean \pm SD, $n=3$, except for Yield, $n=1$.

\begin{tabular}{lrlll}
\hline Formulations & \multicolumn{1}{c}{$D_{v}(\mu \mathrm{m})$} & Yield $(\%)$ & DL $(\%)$ & EE (\%) \\
\hline F1 & $7.3 \pm 1.1$ & 58 & - & - \\
F2 & $4.7 \pm 0.4$ & 51 & - & - \\
F3 & $6.4 \pm 2.4$ & 64 & - & - \\
F4 & $7.0 \pm 2.6$ & 45 & - & - \\
F5 & $6.6 \pm 2.7$ & 66 & - & - \\
F6 & $6.5 \pm 1.8$ & 50 & - & - \\
F7 & $6.4 \pm 1.2$ & 66 & - & - \\
F8 & $5.8 \pm 1.2$ & 50 & - & - \\
F9 & $7.4 \pm 2.6$ & 75 & $43.2 \pm 0.5$ & $108 \pm 1$ \\
F10 & $8.5 \pm 4.2$ & 67 & $39.8 \pm 0.8$ & $120 \pm 3$ \\
F11 & $9.9 \pm 3.6$ & 67 & $42.5 \pm 0.8$ & $106 \pm 2$ \\
F12 & $8.8 \pm 4.2$ & 58 & $42.4 \pm 0.3$ & $128 \pm 1$ \\
F13 & $8.2 \pm 2.6$ & 79 & $43.2 \pm 0.5$ & $108 \pm 1$ \\
F14 & $8.0 \pm 2.8$ & 59 & $40.7 \pm 0.6$ & $123 \pm 2$ \\
F15 & $12.6 \pm 2.8$ & 72 & $46.7 \pm 1.1$ & $117 \pm 3$ \\
F16 & $10.1 \pm 3.7$ & 51 & $41.4 \pm 0.8$ & $125 \pm 2$ \\
\hline
\end{tabular}

process (leading to lower yield), and it was difficult to spray dry those formulations owing to their high viscosity. Therefore, the formulation that was selected was F13 (Table 1). After the optimization step, MS were prepared with alternative crosslinking agents, i.e. GNP, GA or GLY, using the same operating conditions as for F13, but adapting their concentrations to their reactivity. These formulations and F13 were further analyzed by different techniques, whose results are described below. For clarity purposes, F13 is also referred to as MS_LVX_GL in the text that follows. For comparison, unloaded and uncrosslinked $0.5 \%(\mathrm{w} / \mathrm{v})$ chitosan MS (MS_uncross), as well as unloaded MS crosslinked with GL (MS_GL), GNP (MS_GNP), GA (MS_GA) and GLY (MS_GLY) were also prepared using the same operating conditions.

\subsection{MS properties}

\subsubsection{SEM}

The crystalline nature of LVX alone was confirmed by SEM analysis, with the presence of pointed and rod-shaped powder (Fig. 2A). In turn, spherical structures were observed for all the spray dried formulations. The LVX-loaded MS appear to have sizes up to $5 \mu \mathrm{m}$ and are spherical with a uniformly smooth surface, without visible free LVX crystals on the surface (Fig. 2C-J). The appearance is not affected by the crosslinking agents or by the entrapment of LVX. However, results of geometric size for MS crosslinked with GL were higher than those obtained with SEM images which were attributed to the possible agglomeration of MS when dispersed in water.

\subsection{2. $X R D$}

Sharp diffraction peaks of raw materials denoted their crystalline nature. The absence of the sharp peaks of LVX in the XRD spectra of corresponding MS (Fig. 3) indicated that LVX was in amorphous state and/or molecularly dispersed in the MS, irrespective of the crosslinking agent.

\subsubsection{DTA/TGA}

DTA/TGA (Fig. 4) were performed to further characterize the MS formulated with different crosslinking agents. On the LVX thermogram, an endothermic event was observed at $78{ }^{\circ} \mathrm{C}$ corresponding to a weight loss of $2.35 \%(\mathrm{w} / \mathrm{w})$ measured by TGA, that agrees with the theoretical water content $(2.43 \%)$ from the LVX hemihydrate. The endothermic peak at $225^{\circ} \mathrm{C}$ corresponds to the anhydrate LVX melting [48]. For GNP, GA and GLY, the melting temperatures were observed at $125^{\circ} \mathrm{C}[49,50], 100^{\circ} \mathrm{C}$ and $140{ }^{\circ} \mathrm{C}$, respectively. The GA boiling point was observed at $265^{\circ} \mathrm{C}$ [27]. Concerning uncrosslinked and unloaded chitosan MS (MS_uncross), the endothermic peak near $60^{\circ} \mathrm{C}$ corresponds to the absorbed water loss [22]. An exothermic peak was observed above $225^{\circ} \mathrm{C}$, which was attributed to the chemical degradation of chitosan [16,51]. Independently of the crosslinking agent, these two previously mentioned thermal events were observed for LVX-loaded MS with some differences in the shape of peaks and different values of weight loss (TGA, Fig. 4B). Therefore, the dispersion of LVX in the MS was confirmed by the absence of the respective melting peak, being in accordance with the results from XRD [22,16]. With respect to the gravimetric analysis, non-crosslinked MS tend to lose ca. $60 \%$ of the mass up to $300{ }^{\circ} \mathrm{C}$. If the MS are crosslinked, the weight loss is slightly lower. Upon addition of the drug, the percentage weight loss drops to values close to $40 \%$. However, this value indicates a total weight loss somewhat exceeding what would be predictable from the separate components of the MS (ca. 33\%) [49].

\subsubsection{ATR-FTIR}

ATR-FTIR studies were conducted in order to analyze the potential LVX chemical modification in the MS and to evaluate the chemical interactions developed by the crosslinking agents. The LVX spectrum presented the characteristic peaks at 1724 ( $C=0$ acid), 1618 ( $C=0$ carbonyl) and $1289 \mathrm{~cm}^{-1}$ ( $\mathrm{C}-\mathrm{O}$ acid) [52,53]. These three peaks were present in all the LVX-loaded MS, confirming there was no change in the functional groups of LVX after its incorporation, suggesting that no chemical reactions occurred between LVX and other components of the MS (Fig. 5). Concerning unloaded and uncrosslinked MS (MS_uncross), characteristic bands of chitosan were present in the region $3000-3500 \mathrm{~cm}^{-1}$ for amino and hydroxyl groups. Other characteristic absorption peaks were found at $1633 \mathrm{~cm}^{-1}$ corresponding to amide I $(\mathrm{C}=\mathrm{O})$ and $1547 \mathrm{~cm}^{-1}$ to amide II (NH) $[49,54]$. The band observed at $1400 \mathrm{~cm}^{-1}$ may be attributed to the $\mathrm{C}-\mathrm{N}$ or $\mathrm{C}-\mathrm{OH}$ stretch. The two bands at 1064 and $1018 \mathrm{~cm}^{-1}$ correspond to $\mathrm{C}-\mathrm{O}-\mathrm{C}, \mathrm{C}-\mathrm{O}$ and $\mathrm{C}-\mathrm{N}$ stretchings. For unloaded MS, crosslinked with GL, MS_GL, the change in intensity of the band at $1633 \mathrm{~cm}^{-1}$ may be due to the presence of the $\mathrm{C}=\mathrm{N}$ group (Fig. 5) that confirmed the crosslinking reaction, responsible for the formation of the imine, resulting from the reaction of the amine group of chitosan with GL. [27]. With respect to the MS crosslinked with GNP (MS_GNP, Fig. 5), this crosslinking agent reacts with the amine groups of chitosan, which is accompanied by a change in color to dark blue. This is due to the formation of a heterocyclic amine by the nucleophilic substitution by the amino group of chitosan on the C-3 carbon atom of GNP, followed by a ring opening $[49,23]$. GNP showed two intense bands at 1680 and $1620 \mathrm{~cm}^{-1}$ corresponding to the $\mathrm{C}=\mathrm{O}$ and $\mathrm{C}=\mathrm{C}$ stretchings. The 

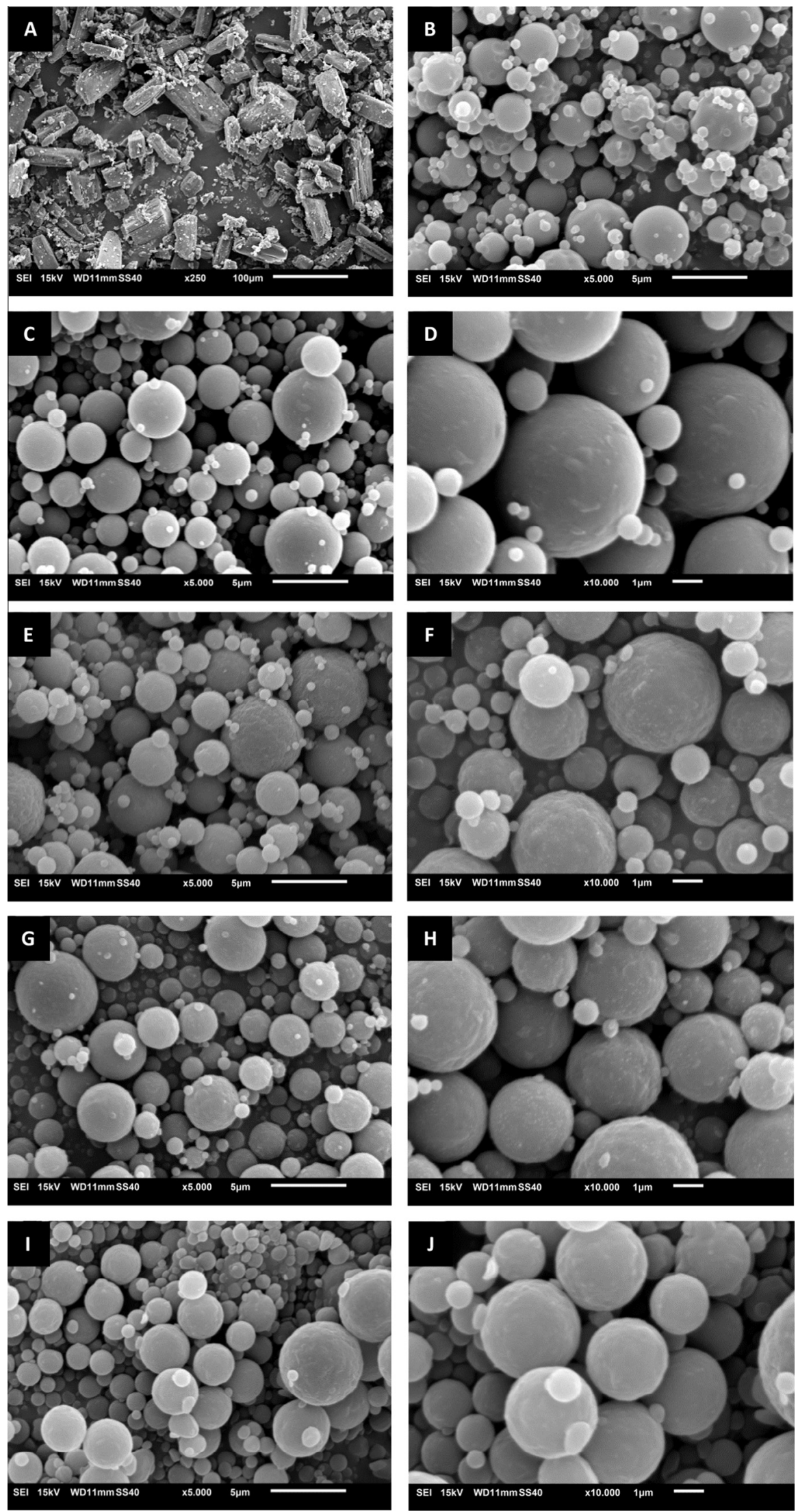

Fig. 2. SEM images of LVX crystals (A), of unloaded uncrosslinked MS (B) and of LVX-loaded MS crosslinked with GL (C, D) (=F13), GLY (E, F), GA (G, H) or GNP (I, J). 


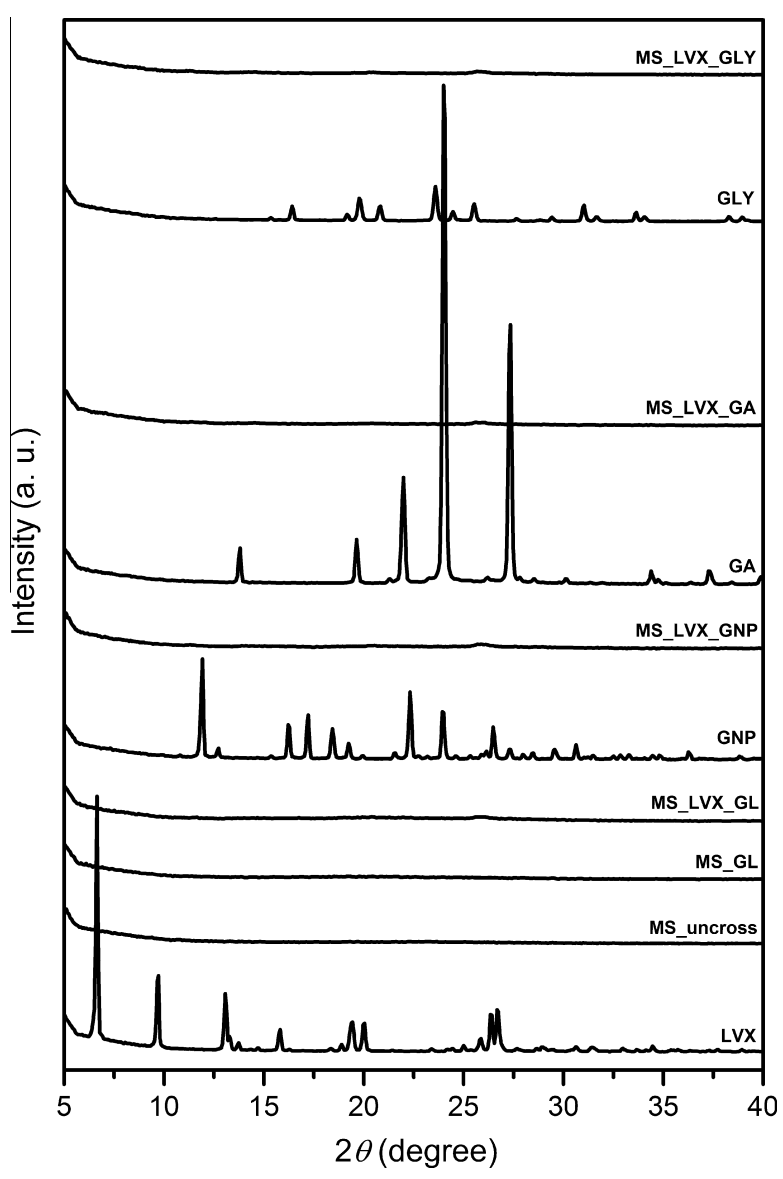

Fig. 3. XRD patterns of raw materials (LVX, GLY, GNP, GA), of unloaded uncrosslinked MS (MS_uncross), of unloaded MS crosslinked with GL $\left(\mathrm{MS} \_\mathrm{GL}=\mathrm{F} 5\right)$, and of LVX-loaded MS crosslinked with GL (MS_LVX_GL = F13), GNP (MS_LVX_GNP), GA (MS_LVX_GA) or GLY (MS_LVX_GLY).

change in the profile in this region in the MS crosslinked with GNP is an indication that the crosslinking actually took place. For MS crosslinked with GA (Fig. 5) no significant changes were observed when comparing uncrosslinked MS (MS_uncross) with MS crosslinked with GA, MS_GA. However, the band at $1696 \mathrm{~cm}^{-1}$ in the GA IR spectrum is no longer present in the MS crosslinked with GA, which could be an indication that a transformation occurred. It has been reported in the literature that ionic interactions between chitosan and GA as well as the hydrogen bond between the carboxylic group of GA and amino group of chitosan are possible [27]. There is paucity of data with respect to the crosslinking reaction of GLY with polymers such as chitosan. Only the interpretation from swelling behavior and release studies have been used to demonstrate its efficacy as a crosslinking agent $[28,29]$. In this case, no significant information can be obtained by comparing the IR spectra (Fig. 5).

\subsubsection{Swelling properties}

LVX-loaded MS crosslinked with GL presented the lowest swelling value, which was constant over time (Table 4). MS crosslinked with the other crosslinkers swelled to a larger extent. With GLY the swelling value was close to $500 \%$. With GNP or GA, swelling values were the highest (around 1000\%) and a dark blue solid-like gel and a slight yellow weak gel were observed, respectively. The higher swelling of GNP- or GA-crosslinked MS compared to GL-crosslinked MS was attributed to lower degrees of crosslinking [55]. El Sherbiny et al. studied the relationship between the swelling properties of MS and their phagocytosis by macrophages
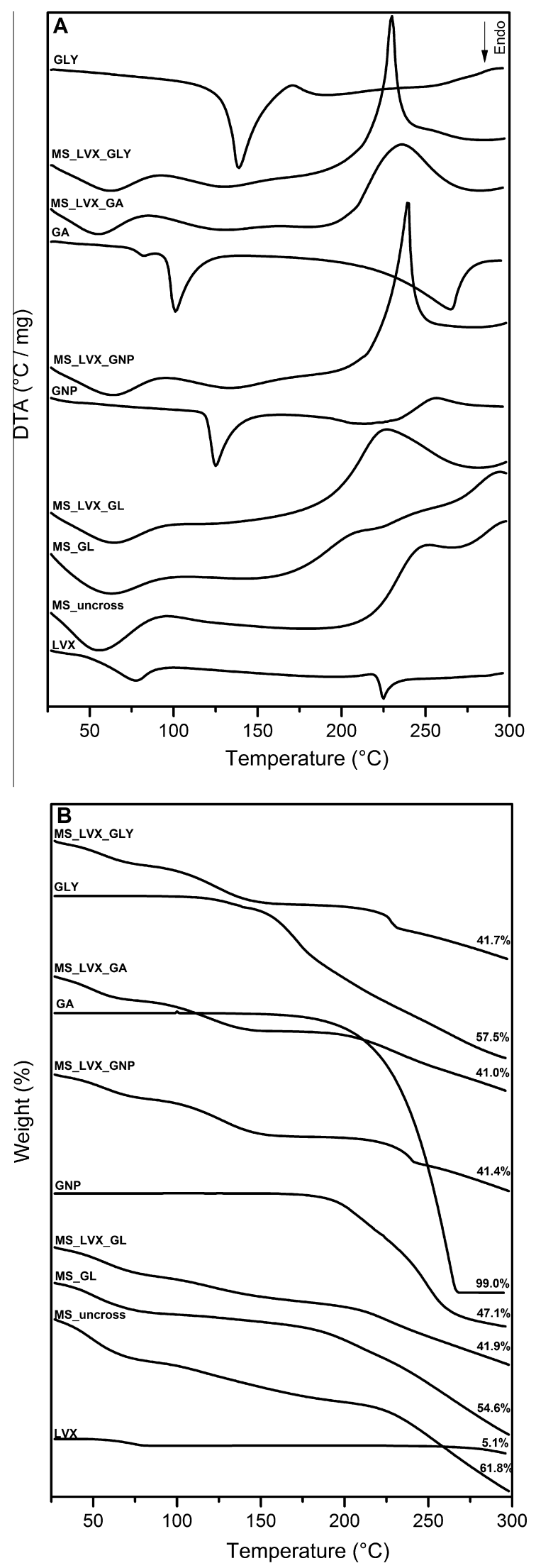

Fig. 4. DTA (A) and TGA (B) thermograms of raw materials (LVX, GLY, GNP, GA), of unloaded uncrosslinked MS (MS_uncross), of unloaded MS crosslinked with GL (MS_GL = F5), and of LVX-loaded MS crosslinked with GL (MS_LVX_GL = F13), GNP (MS_LVX_GNP), GA (MS_LVX_GA) or GLY (MS_LVX_GLY). Total weight loss (\%) is indicated on TGA curves. 


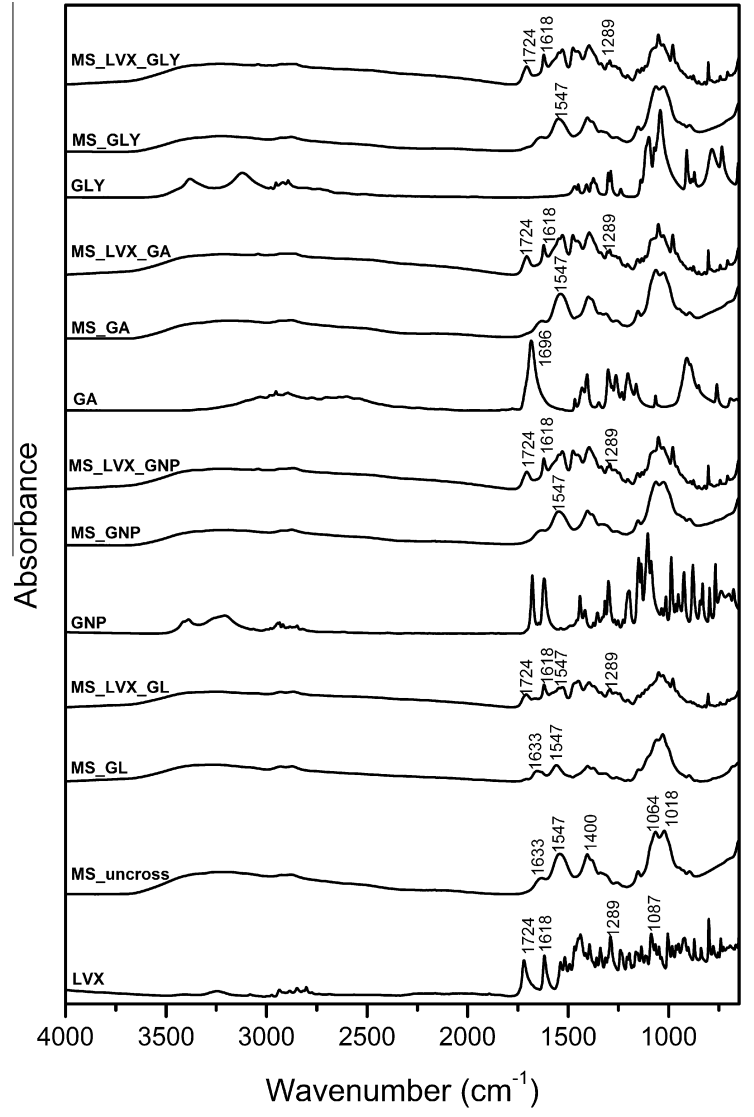

Fig. 5. ATR-FTIR spectra of raw materials (LVX, GLY, GNP, GA, GL), of unloaded uncrosslinked MS (MS_uncross), of unloaded MS crosslinked with GL (MS_GL = F5), GNP (MS_GNP), GA (MS_GA) or GLY (MS_GLY), and of LVX-loaded MS crosslinked with GL (MS_LVX_GL) (=F13), GNP (MS_LVX_GNP), GA (MS_LVX_GA) or GLY (MS_LVX_GLY).

Table 4

MS degree of swelling (\%) at two time points. Results are expressed as mean \pm SD, $n=3$.

\begin{tabular}{llllc}
\hline Formulations & $\begin{array}{l}\text { Crosslinkers and } \\
\text { concentrations (mmol/g }\end{array}$ & \multicolumn{2}{l}{ Swelling (\%) } \\
\cline { 3 - 5 } & chitosan) & & & \\
& & 5 & $243 \pm 23$ & $247 \pm 51$ \\
& Glutaraldehyde & 5 & h \\
MS_LVX_GL (=F13) & Genipin & 0.2 & $935 \pm 14$ & $1154 \pm 47$ \\
MS_LVX_GNP & Glutaric acid & 1 & $991 \pm 67$ & $1097 \pm 113$ \\
MS_LVX_GA & DL-Glyceraldehyde & 1 & $458 \pm 24$ & $535 \pm 9$ \\
MS_LVX_GLY & & & \\
\hline
\end{tabular}

in vitro and showed that MS of swelling values $\geqslant 1000 \%$ were dramatically less phagocytosed than nonswellable particles [13]. Therefore, the GNP- and GA-crosslinked MS have a great potential to escape from macrophages once deposited in the lungs.

\subsection{6. $D L(\%)$ and $E E(\%)$}

EE values were around $110 \%$ and $120 \%$, respectively for MS crosslinked with $5 \mathrm{mmol}$ or $10 \mathrm{mmol}$ GL per $\mathrm{g}$ of chitosan (Table 3). Taking into account that the GL boiling point is $101{ }^{\circ} \mathrm{C}$ in aqueous solution [56], we hypothesized that a fraction of GL did not react and evaporated during the spray-drying process, which can explain the high values of the EE (\%). Using GNP, GA and GLY as crosslinkers, the EE were around 100\% (Table 5). Such high EE values allow also concluding that LVX did not appreciably react with the crosslinkers in the preparation process. In what pertains to the DL (\%), the aim was to maximize the content of LVX in
Table 5

Values of Yield (\%), DL (\%) and EE (\%) for MS prepared after the optimization process. Results are expressed as mean $\pm \mathrm{SD}, n=3$. All formulations include LVX with LVX:chitosan preparation ratio of $1: 1(\mathrm{w} / \mathrm{w})$.

\begin{tabular}{lllr}
\hline Formulations & Yield (\%) & DL $(\%)$ & EE $(\%)$ \\
\hline MS_LVX_GNP & 89 & $48.4 \pm 5.8$ & $99 \pm 12$ \\
MS_LVX_GA & 91 & $50.5 \pm 0.3$ & $107 \pm 1$ \\
MS_LVX_GLY & 88 & $50.8 \pm 0.9$ & $106 \pm 2$ \\
\hline
\end{tabular}

Table 6

In vitro aerosolization properties of MS (values are expressed as means $\pm \mathrm{SD}, n=3$ ).

\begin{tabular}{lllll}
\hline Formulations & ED (\%) & FPF $(\%)$ & FPD $(\mathrm{mg})$ & MMAD $(\mu \mathrm{m})$ \\
\hline MS_LVX_GL (=F13) & $89.8 \pm 1.1$ & $23.7 \pm 5.3$ & $1.2 \pm 0.2$ & $8.4 \pm 2.3$ \\
MS_LVX_GNP & $89.5 \pm 0.7$ & $31.8 \pm 1.3$ & $2.2 \pm 0.5$ & $5.4 \pm 0.2$ \\
MS_LVX_GA & $91.9 \pm 1.9$ & $32.3 \pm 4.0$ & $2.3 \pm 0.3$ & $5.9 \pm 1.2$ \\
MS_LVX_GLY & $88.0 \pm 3.2$ & $27.3 \pm 1.1$ & $1.6 \pm 0.1$ & $7.4 \pm 1.1$ \\
\hline
\end{tabular}

order to minimize the amount of powder material to be administered into the lungs. DL ranged from 40.7 to $55.8 \%(\mathrm{w} / \mathrm{w}$ ) (Tables 4 and 6). An efficient dose with inhaled LVX solution, MP-376, (Aeroquin $^{\mathrm{TM}}$ ) was shown to range from 120 to $240 \mathrm{mg}$ (once or twice a day) [57,7]. With the present MS, the amount of material to administer such a dose would range from 250 to $500 \mathrm{mg}$ a day, considering a therapeutic efficiency equivalent to the aerosolized LVX solution. This deserves to be evaluated in terms of safety. Alternatively, the present LVX-loaded MS may be used as a short-term therapeutic option for out-of-home patients, as an alternative to fastidious and demanding aerosol therapy with liquid formulations [58].

\subsection{In vitro studies}

\subsubsection{In vitro deposition studies using NGI}

The experimental conditions for aerodynamic determinations were selected to ensure high aerosol performance. The $60 \mathrm{~L} / \mathrm{min}$ flow rate was higher than that considered to be attainable by patients using a Handihaler ${ }^{\circledR}$ device, but it provided a high pressure drop through the inhaler (around $8 \mathrm{kPa}$ ) [59], thus a high energy input to disperse efficiently the microsphere powder [60]. In addition, the pump was turned on twice to ensure complete emptying of the capsules. Results of the selected formulations are presented in Table 6. All the formulations showed a high dispersibility with ED values around $90 \%$, indicating that the microsphere powder was efficiently emitted from the DPI. MMAD values were dependent on the crosslinker used. For MS crosslinked with GNP and GA, MMAD

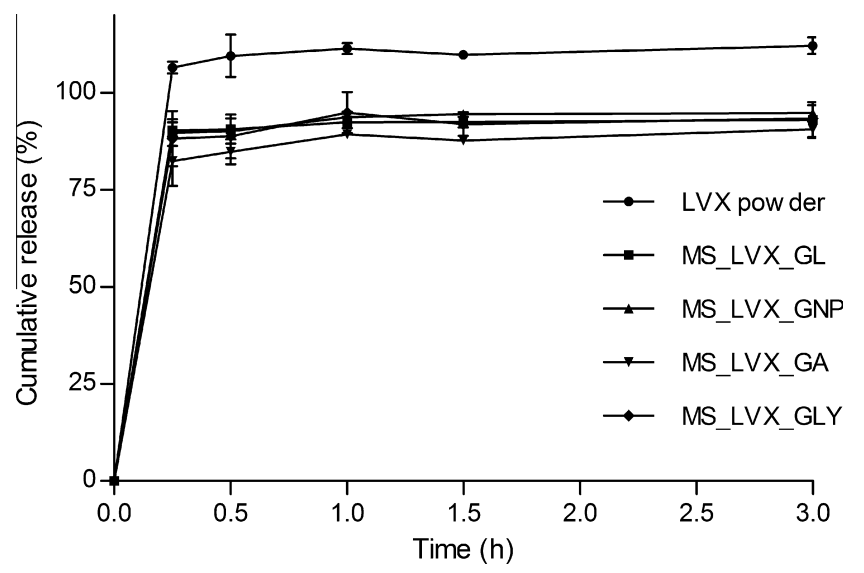

Fig. 6. In vitro release profiles of LVX-loaded MS. MS_LVX_GL corresponds to F13. 
Table 7

MIC and disk diffusion test results from LVX and loaded MS crosslinked with GL, GNP, GA and GLY.

\begin{tabular}{|c|c|c|c|c|}
\hline \multirow[t]{2}{*}{ Formulation or compound } & \multicolumn{2}{|l|}{$\mathrm{MIC}(\mathrm{mg} / \mathrm{L})$} & \multicolumn{2}{|c|}{$\begin{array}{l}\text { Inhibition zone } \\
\text { diameter }(\mathrm{mm})^{\mathrm{a}}\end{array}$} \\
\hline & CF2_2004 & CF7_2005 & CF2_2004 & CF7_2005 \\
\hline Chitosan & - & - & 0 & 0 \\
\hline LVX & 0.625 & 0.625 & 26 & 22 \\
\hline MS_LVX_GL (=F13) & 0.625 & 0.625 & 20 & 24 \\
\hline MS_LVX_GNP & 0.625 & 0.312 & 20 & 23 \\
\hline MS_LVX_GA & 0.625 & 0.625 & 20 & 24 \\
\hline MS_LVX_GLY & 0.625 & 0.625 & 18 & 25 \\
\hline
\end{tabular}

a Values obtained from theoretical value of $0.5 \mu \mathrm{g} / \mu \mathrm{L} \mathrm{LVX}$.

values were found around $5 \mu \mathrm{m}$, a value satisfactory for delivery to the conductive zone of the lungs (trachea, bronchi and terminal bronchioles) where the $P$. aeruginosa infection is mainly present [2]. These results were consistent with SEM analyses (Fig. 2). However, for MS crosslinked with GL and GLY, MMAD values were close to $8 \mu \mathrm{m}$. For MS prepared with GL, MMAD mean values exceeding the range of the higher aerodynamic cutoff plate consist of extrapolated values established from the cumulated mass percentage distribution. Since SEM images revealed an MS diameter close to $5 \mu \mathrm{m}$ (Fig. 2C and D, and E and F respectively), the MS may not fully de-aggregate in the inhaler despite the high pressure drop applied [61]. For MS crosslinked with GNP, GA and GLY, FPF was high (around 30\%), i.e. in the upper values reported for marketed powder formulations for inhalation [62]. For MS crosslinked with GL, FPF was slightly lower. Thus, in general, the MS obtained in the present work should be efficient to deliver LVX into the lungs.

\subsection{2. $\mathrm{LVX}$ release from $M S$}

All the formulations resulted in an almost immediate release of LVX (Fig. 6). This allows concluding that chitosan crosslinking has no impact upon LVX release. This was attributed to the high solubility in water of LVX associated with the high drug loading and with the large surface area developed by the micrometric-sized particles, which allowed the rapid diffusion of the drug from the MS matrix. In addition, the amorphous state of LVX, evidenced by XRD and DTA analyses, is usually associated with higher dissolution rate compared to crystalline state [38]. Similar results were obtained by Corrigan et al. by the preparation of salbutamol sulfate loaded in formaldehyde-crosslinked chitosan MS [63] with no difference between crosslinked and non-crosslinked systems. Despite some authors having reported drug controlled release with crosslinked chitosan matrices, it is usually observed for drugs with low hydrophilicity and/or at low drug content values [16,22]. In this work, we found that with a hydrophilic high soluble drug as LVX, and with high values of drug content it is not possible to obtain a controlled release profile using a crosslinked chitosan.

\subsubsection{Antibacterial activity of MS}

Antibacterial activity of free LVX, chitosan and selected LVX-loaded MS was evaluated for two bacterial isolates of $P$. aeruginosa (CF2_2004 and CF7_2005) by the broth microdilution method. The aim was to investigate whether the LVX activity is altered by encapsulation in MS, and to understand whether there is some antibacterial synergistic effect due to chitosan and LVX in loaded MS. The MIC value for LVX was $0.625 \mathrm{mg} / \mathrm{L}$ for both bacterial isolates. Regarding the MS, the MIC value of $0.625 \mathrm{mg} / \mathrm{L}$ was observed for CF2_2004, regardless of the crosslinking agent that was used. Very similar results were obtained from CF7_2005, but MS crosslinked with GNP demonstrated a lower MIC value $(0.312 \mathrm{mg} / \mathrm{L})$, see Table 7 . This effect may be due to the presence of some uncrosslinked GNP, taking into consideration that this crosslinker has already been reported as an antimicrobial and anti-inflammatory agent $[50,64]$. Chitosan alone did not exhibit any antibacterial activity against the two isolates that were used (bacterial growth was observed for all the concentrations in the range $0.078-5 \mathrm{mg} / \mathrm{L}$ ). Actually, some antibacterial activity has been recently reported for chitosan, but it was observed only at higher concentrations such as $0.0125 \%(\mathrm{w} / \mathrm{v})$ [65] and $0.05 \%(\mathrm{w} / \mathrm{v})$ [14] for $P$. aeruginosa. The similarity between the results from LVX and loaded MS is in accordance with the fast drug release that was already explored and it is apparent that LVX can be safely encapsulated in MS without losing its antibacterial activity. Concerning the results from the disk diffusion test, which was used to evaluate bacterial susceptibility, very similar diameters of the inhibition zone were obtained for free LVX and all the MS. In fact, all the values were in excess of $17 \mathrm{~mm}$ (Table 7), meaning that the bacterial isolates CF2_2004 and CF7_2005 may be classified as "sensitive" to LVX [41]. No inhibition zone was observed for chitosan.

\section{Conclusions}

MS crosslinked with GL were prepared by spray drying and according to a factorial design for the size optimization. After this step, MS with high LVX loading and using less toxic crosslinking agents (GNP, GA and GLY) were successfully prepared to control swelling properties. Entrapped LVX was shown to be in an amorphous or well dispersed state within the polymeric matrix. All the MS formulations gave similar immediate release profiles in vitro. Their antibacterial activities against bacterial isolates of $P$. aeruginosa were equivalent to free LVX. The highest degree of swelling was obtained with MS crosslinked with GNP and GA, which make these MS the best candidates to escape from phagocytosis. In addition, these MS possess satisfactory aerodynamic properties for lung delivery as dry powder. They therefore may offer an easy-to-use alternative to LVX solution for inhalation.

\section{Conflict of interest}

The authors report no conflict of interests.

\section{Acknowledgments}

The authors thank FCT (Fundação para a Ciência e a Tecnologia, Portugal) for the financial support through the grant SFRH/BD/80307/2011. DTA/TGA, XRD and ATR-FTIR analyses were performed at the University of Poitiers, Pôle Commun de Mesures Physico-chimiques platform. Spray-drying experiments were carried out in Biocydex, Poitiers. The authors thank Patrice Gobin and Christophe Adier for their technical assistance in HPLC measurements.

\section{References}

[1] M.Y. Ng, W. Flight, E. Smith, Pulmonary complications of cystic fibrosis, Clin. Radiol. 69 (3) (2014) e153-e162, http://dx.doi.org/10.1016/j.crad.2013.10.023.

[2] N. Høiby, Recent advances in the treatment of Pseudomonas aeruginosa infections in cystic fibrosis, BMC Med. 9 (1) (2011) 32-38, http://dx.doi.org/ 10.1186/1741-7015-9-32.

[3] C. Stockmann, C.M.T. Sherwin, K. Ampofo, M.G. Spigarelli, Development of levofloxacin inhalation solution to treat Pseudomonas aeruginosa in patients with cystic fibrosis, Ther. Adv. Respir. Dis. 8 (1) (2014) 13-21, http:// dx.doi.org/10.1177/1753465813508445.

[4] D.E. Geller, Aerosol antibiotics in cystic fibrosis, Respir. Care 54 (5) (2009) 658670.

[5] S. Kirkby, K. Novak, K. McCoy, Aztreonam (for inhalation solution) for the treatment of chronic lung infections in patients with cystic fibrosis: an evidence-based review, Core Evidence 6 (2011) 59-66.

[6] G.S. Sawicki, J.E. Signorovitch, J. Zhang, D. Latremouille-Viau, M. von Wartburg, E.Q. Wu, L. Shi, Reduced mortality in cystic fibrosis patients treated with 
tobramycin inhalation solution, Pediatr. Pulmonol. 47 (1) (2012) 44-52, http:// dx.doi.org/10.1002/ppul.21521.

[7] Foundation CF, Drug Development Pipeline, 2012. <http://www.cff.org/ research/DrugDevelopmentPipeline/> (accessed 07.01.15).

[8] X.M. Zeng, G.P. Martin, C. Marriott, The controlled delivery of drugs to the lung, Int. J. Pharm. 124 (2) (1995) 149-164, http://dx.doi.org/10.1016/03785173(95)00104-q.

[9] A. Saigal, W.K. Ng, R.B.H. Tan, S.Y. Chan, Development of controlled release inhalable polymeric microspheres for treatment of pulmonary hypertension, Int. J. Pharm. 450 (1-2) (2013) 114-122, http://dx.doi.org/10.1016/ j.ijpharm.2013.04.011.

[10] M.C. Gaspar, W. Couet, J.C. Olivier, A.A.C.C. Pais, J.J.S. Sousa, Pseudomonas aeruginosa infection in cystic fibrosis lung disease and new perspectives of treatment: a review, Eur. J. Clin. Microbiol. Infect. Dis. 32 (10) (2013) 12311252, http://dx.doi.org/10.1007/s10096-013-1876-y.

[11] C. Loira-Pastoriza, J. Todoroff, R. Vanbever, Delivery strategies for sustained drug release in the lungs, Adv. Drug Deliv. Rev. 75 (2014) 81-91, http:// dx.doi.org/10.1016/j.addr.2014.05.017.

[12] J. Du, I. El-Sherbiny, H. Smyth, Swellable ciprofloxacin-loaded nano-in-micro hydrogel particles for local lung drug delivery, AAPS PharmSciTech 15 (6) (2014) 1535-1544, http://dx.doi.org/10.1208/s12249-014-0176-x.

[13] I.M. El-Sherbiny, S. McGill, H.D. Smyth, Swellable microparticles as carriers for sustained pulmonary drug delivery, J. Pharm. Sci. 99 (5) (2010) 2343-2356.

[14] M.S. Benhabiles, R. Salah, H. Lounici, N. Drouiche, M.F.A. Goosen, N. Mameri, Antibacterial activity of chitin, chitosan and its oligomers prepared from shrimp shell waste, Food Hydrocolloids 29 (1) (2012) 48-56, http://dx.doi.org/ 10.1016/j.foodhyd.2012.02.013.

[15] D. Raafat, K. von Bargen, A. Haas, H.-G. Sahl, Insights into the mode of action of chitosan as an antibacterial compound, Appl. Environ. Microbiol. 74 (12) (2008) 3764-3773, http://dx.doi.org/10.1128/aem.00453-08.

[16] H. Feng, L. Zhang, C. Zhu, Genipin crosslinked ethyl cellulose-chitosan complex microspheres for anti-tuberculosis delivery, Colloids Surf., B 103 (2013) 530-537, http://dx.doi.org/10.1016/j.colsurfb.2012.11.007.

[17] A. Bigi, G. Cojazzi, S. Panzavolta, K. Rubini, N. Roveri, Mechanical and thermal properties of gelatin films at different degrees of glutaraldehyde crosslinking, Biomaterials 22 (8) (2001) 763-768, http://dx.doi.org/10.1016/S01429612(00)00236-2.

[18] A. Bigi, G. Cojazzi, S. Panzavolta, N. Roveri, K. Rubini, Stabilization of gelatin films by crosslinking with genipin, Biomaterials 23 (24) (2002) 4827-4832, http://dx.doi.org/10.1016/S0142-9612(02)00235-1.

[19] C.A. Ventura, S. Tommasini, E. Crupi, I. Giannone, V. Cardile, T. Musumeci, G. Puglisi, Chitosan microspheres for intrapulmonary administration of moxifloxacin: interaction with biomembrane models and in vitro permeation studies, Eur. J. Pharm. Biopharm. 68 (2) (2008) 235-244, http:// dx.doi.org/10.1016/j.ejpb.2007.05.011.

[20] M. Abdel Mouez, N.M. Zaki, S. Mansour, A.S. Geneidi, Bioavailability enhancement of verapamil $\mathrm{HCl}$ via intranasal chitosan microspheres, Eur. J. Pharm. Sci. 51 (2014) 59-66, http://dx.doi.org/10.1016/j.ejps.2013.08.029.

[21] M.D. Dhanaraju, S. Elizabeth, T. Gunasekaran, Triamcinolone-loaded glutaraldehyde cross-linked chitosan microspheres: prolonged release approach for the treatment of rheumatoid arthritis, Drug Deliv. 18 (3) (2011) 198-207.

[22] S. Ramachandran, S. Nandhakumar, M.D. Dhanaraju, Formulation and characterization of glutaraldehyde cross-linked chitosan biodegradable microspheres loaded with famotidine, Trop. J. Pharm. Res. 10 (3) (2011) 309-316, http://dx.doi.org/10.4314/tjpr.v10i3.13.

[23] F.-L. Mi, S.-S. Shyu, C.-K. Peng, Characterization of ring-opening polymerization of genipin and $\mathrm{pH}$-dependent cross-linking reactions between chitosan and genipin, J. Polym. Sci., Part A: Polym. Chem. 43 (10) (2005) 1985-2000, http:// dx.doi.org/10.1002/pola.20669.

[24] C. Nishi, N. Nakajima, Y. Ikada, In vitro evaluation of cytotoxicity of diepoxy compounds used for biomaterial modification, J. Biomed. Mater. Res. 29 (7) (1995) 829-834.

[25] H.W. Sung, R.N. Huang, L.L. Huang, C.C. Tsai, In vitro evaluation of cytotoxicity of a naturally occurring cross-linking reagent for biological tissue fixation, J. Biomater. Sci. Polym. Ed. 10 (1) (1999) 63-78.

[26] T. Mitra, G. Sailakshmi, A. Gnanamani, Could glutaric acid (GA) replace glutaraldehyde in the preparation of biocompatible biopolymers with high mechanical and thermal properties?, J Chem. Sci. 126 (1) (2014) 127-140, http://dx.doi.org/10.1007/s12039-013-0543-2.

[27] G. Sailakshmi, M. Tapas, C. Suvro, A. Gnanamani, Chemistry behind the elastic nature of the biomaterial prepared using oxidized form of glutaraldehyde and chitosan - an approach at 2D and 3D level, Int. J. Life Sci. Med. Res. 4 (2) (2013) 64-75, http://dx.doi.org/10.5963/LSMR0302004.

[28] B.F. Oliveira, M.H.A. Santana, M.I. Ré, Spray-dried chitosan microspheres crosslinked with D,L-glyceraldehyde as a potential drug delivery system: preparation and characterization, Braz. J. Chem. Eng. 22 (2005) 353-360.

[29] M.A. Vandelli, F. Rivasi, P. Guerra, F. Forni, R. Arletti, Gelatin microspheres crosslinked with D,L-glyceraldehyde as a potential drug delivery system: preparation, characterisation, in vitro and in vivo studies, Int. J. Pharm. 215 (12) (2001) 175-184, http://dx.doi.org/10.1016/S0378-5173(00)00681-5.

[30] B. Conti, T. Modena, I. Genta, P. Perugini, F. Pavanetto, A proposed new method for the crosslinking of chitosan microspheres, Drug Deliv. 5 (2) (1998) 87-93, http://dx.doi.org/10.3109/10717549809031383.
[31] P. Piyakulawat, N. Praphairaksit, N. Chantarasiri, N. Muangsin, Preparation and evaluation of chitosan/carrageenan beads for controlled release of sodium diclofenac, AAPS PharmSciTech 8 (4) (2007).

[32] C. Muzzarelli, V. Stanic, L. Gobbi, G. Tosi, R.A.A. Muzzarelli, Spray-drying of solutions containing chitosan together with polyuronans and characterisation of the microspheres, Carbohydr. Polym. 57 (1) (2004) 73-82, http://dx.doi.org/ 10.1016/j.carbpol.2004.04.002.

[33] A. Elzoghby, W. Samy, N. Elgindy, Novel spray-dried genipin-crosslinked casein nanoparticles for prolonged release of alfuzosin hydrochloride, Pharm Res. 30 (2) (2013) 512-522, http://dx.doi.org/10.1007/s11095-012-0897-z.

[34] J.W. Eaton, GNU Octave Software, Version 3.2.3, 2009.

[35] T.V. Doan, W. Couet, J.C. Olivier, Formulation and in vitro characterization of inhalable rifampicin-loaded PLGA microspheres for sustained lung delivery, Int. J. Pharm. 414 (1-2) (2011) 112-117, http://dx.doi.org/10.1016/ j.ijpharm.2011.05.007.

[36] R. Osman, P.L. Kan, G. Awad, N. Mortada, A.-E. El-Shamy, O. Alpar, Spray dried inhalable ciprofloxacin powder with improved aerosolisation and antimicrobial activity, Int. J. Pharm. 449 (1-2) (2013) 44-58, http:// dx.doi.org/10.1016/j.ijpharm.2013.04.009.

[37] V. Jain, D. Prasad, D. Jain, S.K. Mishra, R. Singh, Factorial design-based development of measlamine microspheres for colonic delivery, Biomatter 1 (2) (2011) 182-188

[38] F. Tewes, K.J. Paluch, L. Tajber, K. Gulati, D. Kalantri, C. Ehrhardt, A.M. Healy Steroid/mucokinetic hybrid nanoporous microparticles for pulmonary drug delivery, Eur. J. Pharm. Biopharm. 85 (3, Part A) (2013) 604-613, http:// dx.doi.org/10.1016/j.ejpb.2013.03.02.

[39] M.I. Amaro, F. Tewes, O. Gobbo, L. Tajber, O.I. Corrigan, C. Ehrhardt, A.M. Healy Formulation, stability and pharmacokinetics of sugar-based salmon calcitoninloaded nanoporous/nanoparticulate microparticles (NPMPs) for inhalation, Int J. Pharm. 483 (1-2) (2015) 6-18, http://dx.doi.org/10.1016 j.ijpharm.2015.02.003.

[40] E. Matuschek, D.F. Brown, G. Kahlmeter, Development of the EUCAST disk diffusion antimicrobial susceptibility testing method and its implementation in routine microbiology laboratories, Clin. Microbiol. Infect. 20 (4) (2014) 0255-0266.

[41] CLSI, Performance Standards for Antimicrobial Susceptibility Testing TwentyFourth Informational Supplement, CLSI Document M100-S24, 2014.

[42] W.S. Cheow, M.W. Chang, K. Hadinoto, Antibacterial efficacy of inhalable levofloxacin-loaded polymeric nanoparticles against E. coli biofilm cells: the effect of antibiotic release profile, Pharm. Res. 27 (8) (2010) 1597-1609.

[43] H. Adi, P.M. Young, H.-K. Chan, H. Agus, D. Traini, Co-spray-dried mannitolciprofloxacin dry powder inhaler formulation for cystic fibrosis and chronic obstructive pulmonary disease, Eur. J. Pharm. Sci. 40 (3) (2010) 239-247. http://dx.doi.org/10.1016/j.ejps.2010.03.020.

[44] R. Vehring, Pharmaceutical particle engineering via spray drying, Pharm. Res. 25 (5) (2008) 999-1022, http://dx.doi.org/10.1007/s11095-007-9475-1.

[45] J. Elversson, A. Millqvist-Fureby, G. Alderborn, U. Elofsson, Droplet and particle size relationship and shell thickness of inhalable lactose particles during spray drying, J. Pharm. Sci. 92 (4) (2003) 900-910, http://dx.doi.org/10.1002/ jps.10352.

[46] S. Belotti, A. Rossi, P. Colombo, R. Bettini, D. Rekkas, S. Politis, G. Colombo, A.G. Balducci, F. Buttini, Spray dried amikacin powder for inhalation in cystic fibrosis patients: a quality by design approach for product construction, Int. J. Pharm. 471 (1-2) (2014) 507-515, http://dx.doi.org/10.1016/j.ijpharm.2014.05.055.

[47] K.S. Patel, M.B. Patel, Preparation and evaluation of chitosan microspheres containing nicorandil, Int. J. Pharm. Invest. 4 (1) (2014) 32-37.

[48] E.M. Gorman, B. Samas, E.J. Munson, Understanding the dehydration of levofloxacin hemihydrate, J. Pharm. Sci. 101 (9) (2012) 3319-3330, http:// dx.doi.org/10.1002/jps.23200.

[49] J. Kawadkar, M.K. Chauhan, Intra-articular delivery of genipin cross-linked chitosan microspheres of flurbiprofen: preparation, characterization, in vitro and in vivo studies, Eur. J. Pharm. Biopharm. 81 (3) (2012) 563-572, http:// dx.doi.org/10.1016/j.ejpb.2012.04.018.

[50] X. Zhao, K. Song, S. Wang, Y. Zu, N. Li, X. Yu, Micronization of the pharmaceutically active agent genipin by an antisolvent precipitation process, Chem. Eng. Technol. 36 (1) (2013) 33-42, http://dx.doi.org/10.1002/ ceat.201200036.

[51] A.B. Dhanikula, R. Panchagnula, Development and characterization of biodegradable chitosan films for local delivery of paclitaxel, AAPS J. 6 (3) (2004) 88-99, http://dx.doi.org/10.1208/aapsj060327.

[52] W. Rojanarat, T. Nakpheng, E. Thawithong, N. Yanyium, T. Srichana, Levofloxacin-proliposomes: opportunities for use in lung tuberculosis, Pharmaceutics 4 (3) (2012) 385-412.

[53] V.k. Shahwal, B.K. Dubey, M. Bhoumick, Preformulation study of levofloxacin, Int. J. Adv. Pharm. 1 (1) (2012) 8.

[54] E. Bulut, In-vitro evaluation of ibuprofen-loaded microspheres prepared from novel chitosan/poly(vinyl alcohol) interpenetrating polymer network, Polym.Plast. Technol. Eng. 53 (4) (2014) 371-378, http://dx.doi.org/10.1080/ 03602559.2013.844250.

[55] V.L. Gonçalves, M.C.M. Laranjeira, V.T. Fávere, R.C. Pedrosa, Effect of crosslinking agents on chitosan microspheres in controlled release of diclofenac sodium, Polímeros 15 (2005) 6-12.

[56] M.J. O’Neil (Ed.), The Merck Index - An Encyclopedia of Chemicals, Drugs, and Biologicals, Merck and Co., Inc, Whitehouse Station, NJ, 2006. 
[57] D.E. Geller, P.A. Flume, D. Staab, R. Fischer, J.S. Loutit, D.J. Conrad, Levofloxacin inhalation solution (MP-376) in patients with cystic fibrosis with Pseudomonas aeruginosa, Am. J. Respir. Crit. Care Med. 183 (11) (2011) 1510-1516, http:// dx.doi.org/10.1164/rccm.201008-12930C.

[58] S.B. Fiel, Aerosolized antibiotics in cystic fibrosis: an update, Expert Rev. Respir. Med. 8 (3) (2014) 305-314, http://dx.doi.org/10.1586/ 17476348.2014 .896205$.

[59] J. Shur, S. Lee, W. Adams, R. Lionberger, J. Tibbatts, R. Price, Effect of device design on the in vitro performance and comparability for capsule-based dry powder inhalers, AAPS J. 14 (4) (2012) 667-676, http://dx.doi.org/10.1208/ s12248-012-9379-9.

[60] M.J. Donovan, S.H. Kim, V. Raman, H.D. Smyth, Dry powder inhaler device influence on carrier particle performance, J. Pharm. Sci. 101 (3) (2012) 1097 1107, http://dx.doi.org/10.1002/jps.22824.

[61] T.P. Learoyd, J.L. Burrows, E. French, P.C. Seville, Chitosan-based spray-dried respirable powders for sustained delivery of terbutaline sulfate, Eur. J. Pharm.
Biopharm. $68 \quad$ (2) (2008) 224-234, http://dx.doi.org/10.1016/ j.ejpb.2007.04.017.

[62] I.J. Smith, M. Parry-Billings, The inhalers of the future? A review of dry powder devices on the market today, Pulm. Pharmacol. Ther. 16 (2) (2003) 79-95, http://dx.doi.org/10.1016/S1094-5539(02)00147-5.

[63] D.O. Corrigan, A.M. Healy, O.I. Corrigan, Preparation and release of salbutamol from chitosan and chitosan co-spray dried compacts and multiparticulates, Eur. J. Pharm. Biopharm. 62 (3) (2006) 295-305, http://dx.doi.org/10.1016/ j.ejpb.2005.09.008.

[64] H.-J. Koo, K.-H. Lim, H.-J. Jung, E.-H. Park, Anti-inflammatory evaluation of gardenia extract, geniposide and genipin, J. Ethnopharmacol. 103 (3) (2006) 496-500, http://dx.doi.org/10.1016/j.jep.2005.08.011.

[65] M. Kong, X.G. Chen, K. Xing, H.J. Park, Antimicrobial properties of chitosan and mode of action: a state of the art review, Int. J. Food Microbiol. 144 (1) (2010) 51-63, http://dx.doi.org/10.1016/j.ijfoodmicro.2010.09.012. 